\title{
Pricing Liquid Petroleum Gas in Mexico
}

\author{
Dagobert L. Brito* \\ William Laney Littlejohn** \\ Juan Rosellon***
}

April, 1998

\begin{abstract}
This paper considers the regulation of pricing of liquid petroleum gas in Mexico. We construct a model which incorporates all information essential to the pricing question, and derive relationships which should hold between prices in Mexico and prices in world markets. Prices in Mexico can be tied to the readily observable prices in the United States by a netback rule. However, this rule can lead to incentives to increase the price of domestic liquid petroleum gas by diverting production from the regulated market.
\end{abstract}

Key words; liquid petroleum gas, linear programming, pricing, Mexico, regulation

*Department of Economics [MS-22]

Rice University

6100 Main

Houston, TX 77005

**Littlejohn \& Associates

6433 Sawnee

Houston, TX 77005

***Centro de Investigacion y Docencia Economicas, A.C.

Carret. Mexico Toluca 3655

Lomas de Santa Fe, 01210

Mexico D.F.

The reseach reported in this paper was supported by the Comisión Reguladora de Energía in a grant to the Centro de Investigacion y Docencia Economicas, A.C. 


\section{Introduction}

The economics of oil and gas in Mexico are difficult and many of the issues involved are very subtle. It is not surprising that there is substantial misunderstanding of many of the issues involved. The difficulties arise from three sources. First, the national oil company Petroleos Mexicanos (PEMEX) is a monopoly and many of the markets involved are regulated. Prices are not a good guide for economic decisions as to production.

PEMEX must solve a very difficult programming problem to reach decisions as to quantities produced. Second, oil, gas and natural gas liquids are often produced jointly and in such cases it impossible to allocate costs of production to a specific product. ${ }^{1}$ Finally, the goods produced are almost perfect substitutes as inputs in production. Gas and oil are substitutes in the generation of power; natural gas liquids, gas and oil are substitutes as feedstocks. There is little or no curvature in the marginal rates of technical substitution. There are very difficult problems in regulating prices. The Comisión Reguladora de Energía (Energy Regulatory Commission) has been given the responsibility of regulating the price of liquid petroleum gas (LPG), natural gas and electricity.

This paper considers the means by which the price of LPG in Mexico can be tied to observable world market prices in economically defensible fashion. We begin by considering the essentials of the market for LPGs in North America and the Gulf of Mexico and demonstrate that it is appropriate to tie prices in Mexico to the readily observable LPG prices at Mont Belvieu, Texas. We then demonstrate the detailed linear programming models currently used for the planning of the import, export and distribution of LPG in Mexico can be greatly reduced in dimensionality without loss of information about optimal pricing. This permits the construction of simple transparent policy models which incorporate all information essential to the pricing question. and derive relationships which should hold between prices in Mexico and prices in world markets.

${ }^{1 . S e e ~ M . ~ A . ~ A d e l m a n, ~(1963) . ~}$ 


\section{The North American Liquid Petroleum Gas Market}

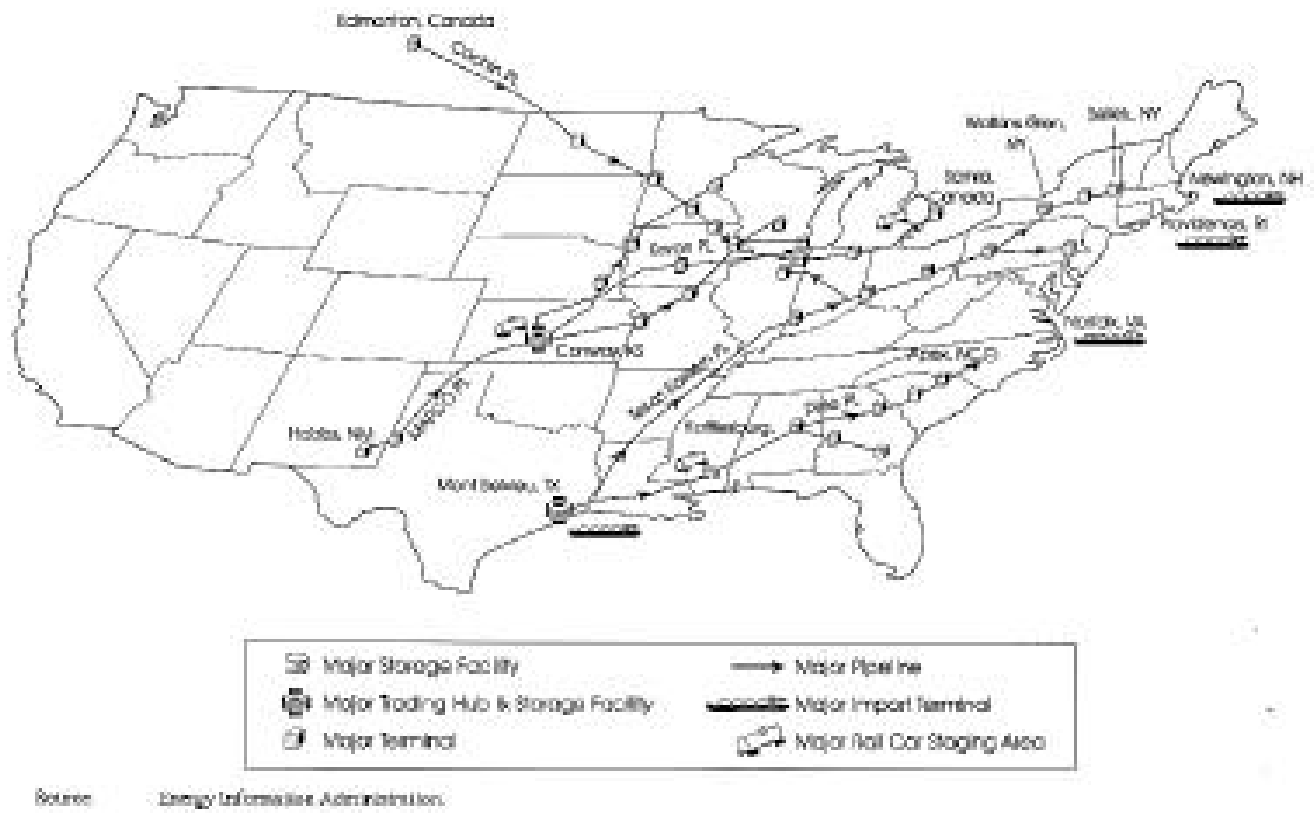

Figure 1

The US is a net importer of LPGs, with net imports running about 100 thousand barrels per day. The majority of this material comes from Canada via pipeline, but significant volumes are imported as waterborne cargoes from Algeria and Venezuela. Depending on market conditions in various parts of the world, the US also imports LPG from Europe (North Sea) and the Middle East (Saudi Arabia, UAE). In the future, as new gas processing facilities come onstream, Nigerian LPG can be expected to flow into the US. Of particular interest to Mexico, is the fact that an annual average of 35 million barrels a day (MBD) of LPGs are imported into U. S. Gulf Coast (USCG) region from outside North America. About 70 percent of this material comes from Algeria, the remainder from Venezuela. These imports are landed at Houston, where they can move into storage facilities at Mont Belvieu.

Mont Belvieu is located 20 miles northeast of Houston and has long been the center of the US market for natural gas liquids (NGL). There are four large fractionators that produce 23 million gallons per day of finished product in Mont Belvieu. Mont Belvieu has 
the largest NGL storage facilities in the world. Located in underground salt domes, the total storage capacity exceeds 4,000 million gallons. The market is large so the price at Mont Belvieu is used for trading in Texas, Louisiana and throughout the Caribbean basin. LPG, butane and propane, are a subset of NGL which include ethane, isobutane, and natural gasoline.

LPG from South America and North Africa is also traded at Mont Belvieu. One of the reasons that LPG trades in an international market is that NGL becomes liquid at temperature of about 0 degrees F. By contrast, natural gas becomes liquid at about -275 degrees F. Thus, it is relatively cheap to liquefy and transport LPG. It costs about $\$ 5.00$ to ship a ton of LPG 1000 miles by sea. This is approximately \$.10 per MMBTU (million BTU) or $\$ .02$ a gallon. The cost of transporting LNG a distance of 1000 miles by sea is approximately $\$ .30$ per MMBTU with a fixed cost of liquefaction and regasification of approximately $\$ 1.40$ to $\$ 1.85 .^{2}$

It should be noted that there is considerable seasonal variation in these imports. In winter, LPG prices in Europe typically rise sufficiently to attract all of the waterborne LPG available from Africa and South America. Under these conditions, it becomes uneconomic to ship this material to the USGC, and imports cease. In summer, however, European prices drop, imports into the US become attractive, and some 50-60 MBD moves into the USGC.

When the US is importing LPG into the USGC, prices at Mont Belvieu should equate to the landed cost of imports (including terminal costs) ${ }^{3}$. Noting further that the sailing distance from Algeria to Pajaritos (c. 5500 n.m.) differs only slightly from that from Algeria to Houston (c. 5400 n.m.), the landed cost of imports into Pajaritos should be approximately the same as the landed cost in Houston, differing only by the amount of the

2.See M. D. Tusiani (1997).

3. Butane imported to the U.S.is used as a feedstock in petro-chemicals and must be fractionated into normal and iso-butane before entering the market. This should be treated as an addition to terminal costs for butane imported into the U.S. LPG in mexico is used as a source of heat and fractionation is not necessary at Pajaritos 
differences in terminal costs. Consequently, one would expect the price of LPG at Pajaritos to be the same as the price at Mont Belvieu.

When prices of African and South American LPG are too high to permit imports into the US, Mont Belvieu may well become the most economic source of product for import into Pajaritos. Under these conditions, one would expect the landed cost of imports at Pajaritos (and the price) to be approximately Mont Belvieu plus 2.5 to 3 cents per gallon. ${ }^{4}$

Mexico imports LPG by pipeline and truck along its northern border. These imports are of product which would otherwise flow by pipeline into the market in the interior of the United States. Thus, to assess prices at the border, and their magnitude relative to prices at Mont Belvieu it is necessary to consider the pattern of distribution of LPGs in the US market. As can be quickly ascertained from the attached map ( Figure 1), there are two major storage points for LPGs in the United States, Mont Belvieu and Conway, Kansas. LPG moves by pipeline from Mont Belvieu into the midwest and eastern portions of the US. Product moves from Conway into the midwest, where it must compete with material coming up Mont Belvieu and imports coming in by pipeline from Canada. Given the locations of Conway and Mont Belvieu relative to their competition point in the Chicago region, one would expect LPG prices at Conway to be approximately the same as they are in Mont Belvieu. This indeed turns out to be the case most of the time, as can be seen in the following graph prepared by the US Energy Information Administration. (see Figure 2)

\footnotetext{
4. This number was suggested as a reasonable approximation by Purvin and Gertz. It should be noted that the exact cost of moving LPG will depend on the demand and supply conditions in the charter market for LPG carriers.
} 


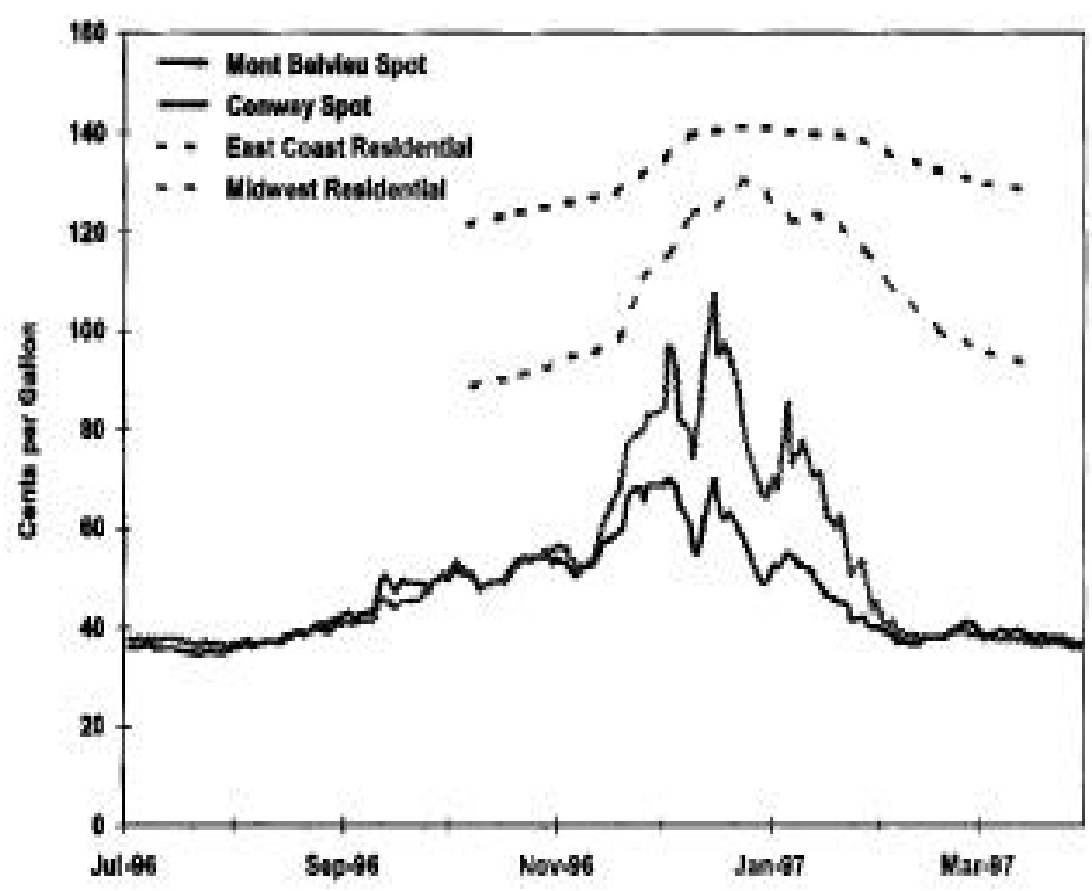

Source: Energy Information Agency

Figure 2

In the winter of 1996-97, low propane stocks, high crop-drying demand in the fall, and cold weather combined to create a shortage of propane in markets served by Conway, which could not be reached by product from Mont Belvieu due to pipeline limitations. Consequently, Conway prices reached levels significantly higher than those in Mont Belvieu. However, this is a highly unusual situation, and under normal circumstances, one finds the price of propane at Conway to be essentially the same as Mont Belvieu, i.e Mont Belvieu even.

Natural gas liquids are extracted at gas processing plants in New Mexico and West Texas. However, there is insufficient capacity in the region to fractionate all these liquids into marketable products including propane and butane. Thus, to meet product demand in the area LPGs must flow back to the region from fractionation plants elsewhere, e.g. Conway. Consequently, one should expect the price of LPG at the Mexican border to be equal to Conway (or equivalently, Mont Belvieu) plus transportation costs of approximately 3 cent per gallon. 


\section{A Model for Pricing Liquid Petroleum Gas}

PEMEX uses a very large programing model to plan production and to price LPG

in Mexico. ${ }^{5}$ This model is very general and very detailed. The duals of the model are the values of the product and the cost of meeting the demands. However, the model is too detailed to be very transparent as to the relationship between the variables. The key variables of interested are the duals associated with the stocks. Large linear models are very easy to compute, but results can be less than transparent. Fortunately, the maximum theorem permits us to show that large programming models can be reduced to a models whose dimensionality is that of the input and constraint set. (See Appendix) This model can be solved analytically and permit a clear understanding as to the implications of various policy choices on the price of gas.

Any path through a network that connects a source of gas to a point of demand is a Hotelling line. This basic concept permits the construction of models for studying the implications of pricing policy for LPG. The price can be derived from the concept of Ricardian rents. As long as gas is free to flow the price of gas must equal the price at the source plus the cost of gas of moving gas to the point of demand. Any other price creates the possibility of profits from arbitrage.

Consider the stylized pipeline in Figure 3 below

5. See Comisión Reguladora de Energía (1997) 


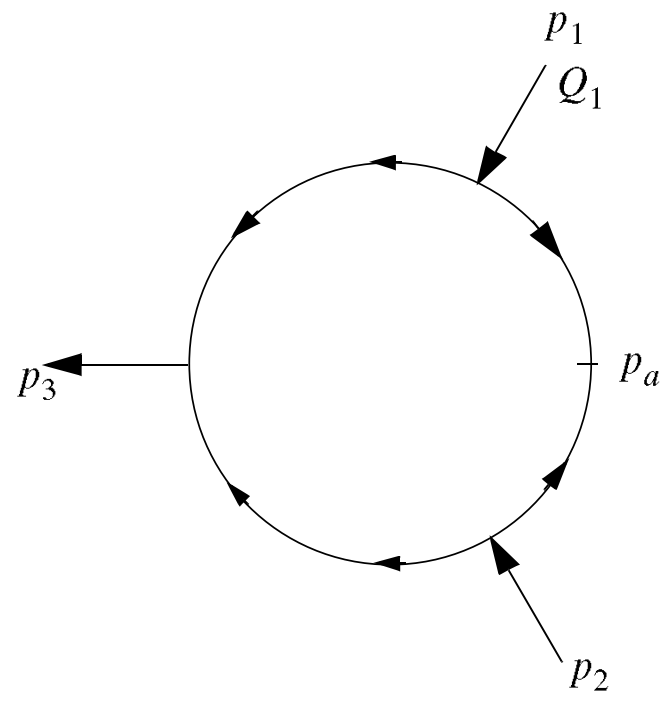

Figure 3

Assume that the pipeline is a circle normalized to a circumference of 3 . The cost of transporting gas is $c$ per unit of length and there is unit demand on the circle uniformly distributed. There are three equally spaced nodes on the pipeline. Node 1 is a connection to a source $Q_{1}$. Node 2 is located 1 unit from Node 1 and is a connection to a competitive market supply at a price $p_{2}$. Node 3 is located 1 unit from Node 1 and is a connection to a competitive market demand at a price $p_{3}$. If flow through the pipeline is not constrained, then market equilibrium requires that $p_{3}=p_{2}+c$. The price at Node 1 is $p_{3}-c$. The price at the arbitrage point, $p_{a}$, midway between Node 1 and Node 2, is $p_{a} \quad p_{1} \cdot \frac{c}{2}=p_{2}+\frac{c}{2}$. We can map this circle into a line to get the price gradient. 


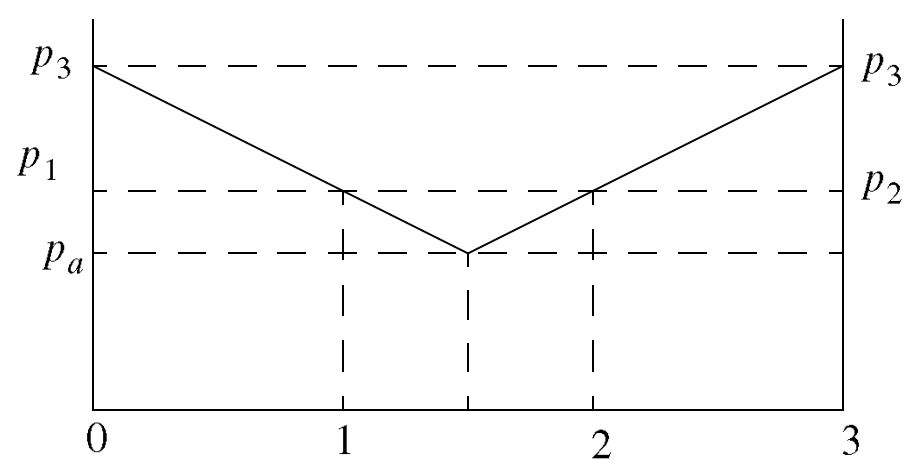

Figure 4

The point at Node 3 in the circle is mapped into the end points of the line at 0 and 3. The price declines uniformly from each of the endpoints until the center of the line which is the arbitrage point.

\section{Pricing LPG in Mexico}

The structure of imports, exports and production in Mexico is depicted in Figure 5 below. 


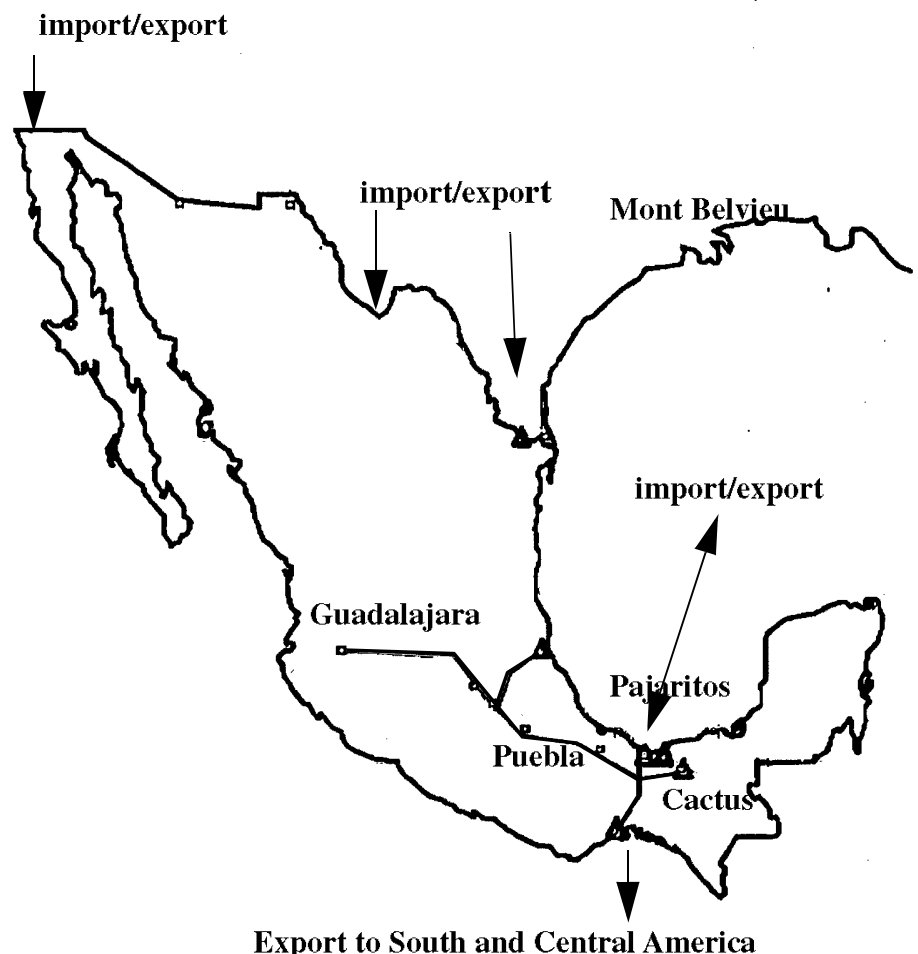

Figure 5

LPG is produced in the oil fields in southern Mexico near Cactus. LPG is imported and exported at Pajaritos by sea. LPG is also exported by sea to Central and South America from the Pacific coast. It is imported on the U.S.-Mexico border by pipeline and truck. Most LPG is consumed in the center of Mexico and this demand is primarily supplied by pipeline. The balance of this demand is mostly in the north of Mexico.

Mexico has some degree of monopoly power in Central and South America. ${ }^{6}$ Further, this is a relatively small market, so the price of exports to South America is not a good guide for pricing gas in Mexico. Thus, exports to South America will be initially ignored as they only complicated the analysis. The implications of export to Central and South America on the price of LPG will be discussed in the next section.

6. Mexico ships LPG to Belize, Costa Rica, Guatemala, Ecuador, as well as to other Latin American countries. 
The essential features of this structure can be characterized by a model with two modes of import, one mode of export, one point of production and demand distributed geographically. The essential features of the distribution system for LPG are represented by the network depicted in Figure 6 below.

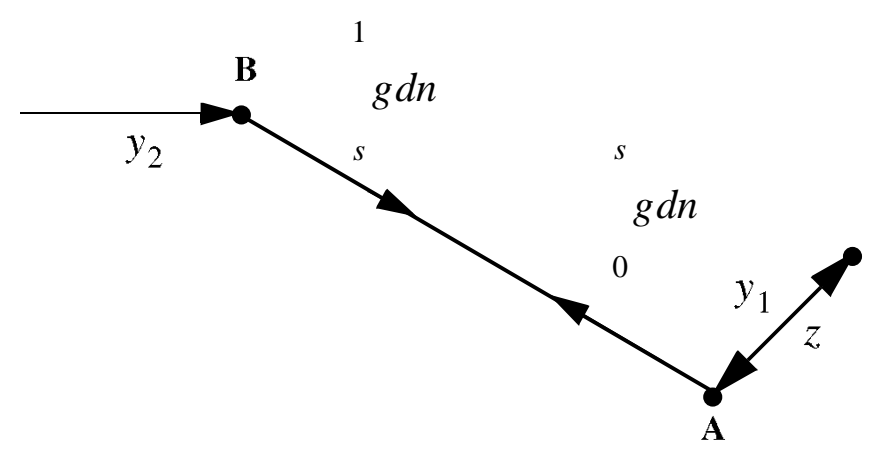

Figure 6

In this network, LPG is produced at point $\mathbf{A}$. This production is denoted by $\mathrm{Q}$. This gas can be transported to points on a line between $\mathbf{A}$ and $\mathbf{B}$. Gas can be imported at points $\mathbf{A}$ and $\mathbf{B}$, these imports are denoted by $y_{1}$ and $y_{2}$ respectively. The price of these imports is $p_{1}$ and $p_{2}$. Gas can be exported at point $\mathbf{A}$, these exports are denoted by $z$. The price of $z$ is $q$. We can think of $\mathbf{A}$ as Pajaritos, the line A-B as demand in Mexico. We will make an assumption similar to Hotellings and assume that the distribution of demand on the line A-B is given by a distribution function $g(s) .{ }^{7}$ The distribution function $g(s)$ is general and could have mass points.Total demand on the line A-B is then given by

7. The problem is originally formulated by PEMEX as minimizing to cost of providing LPG subjected to a demand constraint. For this reason the demand for LPG, as represented by the density function, does not included price. This assumption can be support on two grounds. The solution is determined by the linear Kuhn-tucker conditions given by (6) and (7). Thus the solution is not sensitive to price unless there is a sufficient change in demand so that Mexico switches from importing to exporting LPG. Second, outside of petrochemicals, there are no close substitutes for LPG in Mexico. There have been no studies of the elasticities for LPG in Mexico, but econometric evidence suggests that the short run price elasticity for energy is small. See Dahl (1992). Petrochemicals are outside the regulatory control of the CRE. 


$$
D=\int_{0}^{s} g(n) d n+\int_{s}^{1} g(n) d n
$$

It is assumed that the cost of moving LPG from point $\mathbf{A}$ to a point located at $\mathrm{n}$ is $c_{2} n$ and the cost of moving LPG from point $\mathbf{B}$ to a point located at $\mathrm{n}$ is $c_{2}(1-n)$. The point $\mathrm{s}$ is what is referred to as the arbitrage point, the point where the price of LPG from point $\mathbf{A}$ or point $\mathbf{B}$ is equal.

The objective function of our model is

$$
\min \int_{0}^{s} g(n) c n d n+\int_{s}^{1} g(n)[c(1-n)] d n+p_{2} y_{2}+p_{1} y_{1}-q z
$$

the constraints are:

$$
\begin{gathered}
z+\int_{0}^{s} g(n) d n-Q-y_{1}=0 \\
\quad \int_{s}^{1} g(n) d n-y_{2}=0 .
\end{gathered}
$$

where equation (3) is the resource constraint at point $\mathbf{A}$ and equation (4) is the resource constraint at point B. Equation (4) can be substituted into the objective function and the resulting Lagrangian is

$$
\begin{aligned}
& L=\int_{0}^{s} g(n) c n d n+\int_{s}^{1} g(n)[c(1-n)] d n+p_{2} \int_{s}^{1} g(n) d n+p_{1} y_{1} \\
& -q z+\lambda\left[z+\int_{0}^{s} g(n) d n-Q-y_{1}\right]
\end{aligned}
$$

where $\lambda$ is the dual associated with the value of LPG. The first order conditions are 


$$
\begin{gathered}
p_{1}-\lambda \geq 0, \quad \mathrm{y}_{1}\left[p_{1}-\lambda\right]=0 \\
-q+\lambda \geq 0, \quad z[-q+\lambda]=0
\end{gathered}
$$

The first order condition with respect to $s$, under the assumption that $0<s<1$, can be written as

$$
\lambda=p_{2}+c-2 c s
$$

If we examine inequalities (6), (7) and (8) we see that if imports are positive, the shadow price of LPG at Point $A$ will equal the import price, $\lambda=p_{1}$. If exports at Point $A$ are positive, the shadow price of LPG will equal the export price, $\lambda=q$.

Recall that the "arbitrage point," is the point where the price of imported and domestically produced LPG is equal. The arbitrage point can be determined in one of two ways. First, the arbitrage point can be the result of fixing the price of LPG at Pajaritos and the United States border. ${ }^{8}$ Second, the arbitrage point can be the result of fixing the price at the United States border and the amount of LPG supplied by PEMEX to the domestic market. If the price of LPG at Pajaritos is determined, then the value of $\lambda$ is fixed and equation (8) can be solved for the arbitrage point, $s$,

$$
s=\frac{1}{2}\left(\frac{p_{2}-\lambda}{c}+1\right)
$$

If, on the other hand, there are no imports or exports, then $s$ is determined by the solution of (3) for the condition that $y_{1}$ and $z$ equal to zero,

\footnotetext{
${ }^{8}$ The import price at Pajaritos is either the price of LPG into the Gulf or the price of importing from Mont Belvieu.
} 


$$
\int_{0}^{s} g(n) d n-Q=0 \text {. }
$$

The value of $s$ then gives the price of LPG at Pajaritos through equation (8). This analysis leads to the rules that have been adopted. If LPG is imported or exported at Pajaritos, the the base price of LPG is that cost. If, on the other hand, there are no imports or exports at Pajaritos, the base price of LPG at Pajaritos is given by the rule

$$
\beta=p_{2}+c-2 c s
$$

This is the "netback" rule that the CRE has implemented for pricing LPG in Mexico.

\section{Problems with the structure of incentives}

The CRE has the authority to regulate the price of LPG that is offered for sale in Mexico. It does not have the authority to regulate exports or the use of LPG as petrochemical feed stock. Assume that PEMEX can divert $Z$ of the amount produced from the domestic market at its discretion. If LPG is being exported or imported at Pajaritos, then the price of LPG in the Mexican pipeline system is determined by the price at Pajaritos and the price on the U.S.-Mexico border. However, if there are no imports or exports at Pajaritos, the price of LPG in the Mexican pipeline system is determined by the price on the U.S.-Mexico border. The arbitrage point, $s$ is determined by supply of LPG to the domestic market and is given by

$$
\int_{0}^{s} g(n) d n=Q-Z
$$

where $Z$ is the amount of LPG supplied to the petrochemical industry and/or exported. The base price of LPG at the point of production is then given by (11). If the arbitrage point is moved closer to the point of production, the price goes up by twice to cost of moving the gas. (See equation (11).) This price increase is then imputed on the entire stock of LPG 
produce for domestic consumption. Thus, there are incentives to increase the price of the domestic stock of LPG by exporting production or diverting production to petrochemicals. In fact, PEMEX would have incentives to sell in the unregulated market beyond the point where marginal revenue equals marginal cost.

Let $q(Z)$ be the net price PEMEX receives for sales to non regulated markets and $\beta$ be the net price it receives in the regulated markets as determined by (11). Then the Lagrangian associated with maximizing revenues subject to a production constraint is,

$$
\pi=q(Z) Z+\left(p_{2}+c-2 c s\right) \int_{0}^{s} g(n) d n+\alpha\left[Q-Z-\int_{0}^{s} g(n) d n\right] .
$$

where $\alpha$ is the shadow price of LPG to PEMEX in the revenue maximization problem. The first order conditions are:

$$
\begin{gathered}
\frac{\partial q}{\partial Z} Z+q=\alpha \\
-2 c \int_{0}^{s} g(n) d n+\left(p_{2}+c-2 c s\right) g(s)-\alpha g(s)=0
\end{gathered}
$$

Solving for $\alpha$ we get,

$$
\alpha=\left(p_{2}+c-2 c s\right)-\frac{2 c}{g(s)} \int_{0}^{s} g(n) d n=\beta-\frac{2 c}{g(s)} \int_{0}^{s} g(n) d n
$$

Since the term $\frac{2 c}{g(s)} \int_{0}^{s} g(n) d n>0$, it follows that $\alpha=\frac{\partial q}{\partial Z} Z+q<\beta$. Since the term $\frac{\partial q}{\partial Z} Z+q$ is marginal revenue from nonregulated sales, there is an incentive for PEMEX to 
sell nonregulated LPG beyond the point where marginal revenue is equal to the base price of LPG, $\beta$. Since the base price of LPG reflects the social shadow price of LPG, revenue maximizing on the part of PEMEX could lead to inefficiency.

\section{Conclusions}

This paper studies the implications of linking the Mexican market for LPG to international markets in an efficient manner. The results are consistent with the pricing formula that the Comisión Reguladora de Energía (Energy Regulatory Commission) has established for the pricing of LPG in Mexico. ${ }^{9}$

1. If LPG is imported at Pajaritos, the base price of LPG is the import price.

2. If LPG is exported from Pajaritos, the base price of LPG is the export price.

3. If LPG is not imported or exported at Pajaritos, then the arbitrage point is determined by the balance of LPG that remains after exports. The price of LPG at the arbitrage point is the price of gas at the US-Mexico border plus the cost of moving the LPG to the arbitrage point. The price of LPG at Pajaritos is the price of LPG at the arbitrage point less the cost of moving the LPG from the arbitrage point to Pajaritos.

The arbitrage point is the point where the price of imported from the US-Mexico border and LPG domestically produced LPG is equal. In these two cases, the arbitrage point is established by price at the border and the base price at Pajaritos. The import price would be ship's rail at Mont Belvieu adjusted for difference in terminal costs. Consequently, one would expect the price of LPG at Pajaritos to be the same as the price at Mont Belvieu. When prices of African and South American LPG are too high to permit imports into the US, Mont Belvieu may well become the most economic source of product for import into Pajaritos. Under these conditions, one would expect the price to be approxi-

9.See Comisión Reguladora de Energía (1997). 
mately Mont Belvieu plus 2.5 to 3 cents per gallon.

If the arbitrage point is established by price of gas at the border and the net quantity of LPG supplied to nonregulated markets by PEMEX, then there is an incentive to reduce the supply of LPG by PEMEX by diverting it to nonregulated markets. If there is not an explicit cap on the price of LPG, this could result in a base price for LPG in excess of the market price for imports at Pajaritos.

\section{References}

Adelman, M. A.,1963, The Supply and Price of Natural Gas, (B. Blackwell, Oxford).

Dahl. C., 1992, Energy and Energy Product Demand, Elasticities for the Developing World: A Survey of the Econometric Evidence," Colorado School of Mines, Working Paper 92-14.

Swydan, M., 1996, "Comments on Proposed Policy Decisions Concerning: Tariffs and Pricing, Bidding Procedures for distribution Zones, and Natural Gas Quality Issued by the "Comisión Reguladora de Energía" (CRE) of Mexico", Gas Energy Review. American Gas Association, June, Vol. 24, No. 6.

Tusiani, M. D., 1997, The Petroleum Shipping Industry, (PennWell Publishing Co., Tulsa)

Comisión Reguladora de Energía, 1997. "Resolución de la Comisión Reguladora de Energía sobre la Solicitud de Pemex Gas y Petroquímica Básica Relativa a un Mecanismo Transitorio para la Determinacion de Precios de Gas LP, en tanto se Expide la Metodologia para la Determinación de Precios de Venta de Primera Mano", RES/085/97, MEXICO. (WEBSITE:http://www.cre.gob.mx/registro/resoluciones/1997/ res08597.html) 


\section{Appendix}

We will show that a large programing model can be reduced in dimensionality without loss of information as to the value of the duals. The models used for LPG are typically characterized by the following:

$N$ - demands given by the quantity vector $\mathbf{D}=\left(D_{i}\right), i=1, N$

$M$ - domestic supply points given by the quantity vector $\mathbf{Q}=\left(Q_{j}\right), j=1, M$

$E$ - export demands characterized by the price vector $\mathbf{q}=\left(q_{k}\right), k=1, R$

$K$ - import supply points characterized by the price vector $\mathbf{p}=\left(p_{j}\right), j=M+1, S$

$T$ - transport modes, $t=1, T$

$\mathbf{X}=x_{i j t}$ is the volume transport to demand $i$ from source $j$ using transportation mode $t$ at cost $c_{i j t}$,

$\mathbf{y}=y_{j}$ is the volume of imports from source $j$

$\mathbf{z}=z_{k}$ is the volume of exports to demand $k$.

The objective function PEMEX is to minimize the cost of transporting LPG plus the cost of net imports,

$$
\sum_{i=1}^{N} \sum_{j=1}^{S} \sum_{t=1}^{T} c_{i j t} x_{i j t}+\sum_{j=M+1}^{S} p_{j} y_{j}-\sum_{k=1}^{R} q_{k} z_{k}
$$

The first constraint requires that all demands be satisfied:

$$
\sum_{j=1}^{S} \sum_{t=1}^{T} x_{i j t}=D_{i}, \quad i=1, N
$$

The second constraint requires that domestic production be consumed or exported: 


$$
\sum_{i=1}^{N} \sum_{t=1}^{T} x_{i j t}+z_{j}=Q_{j} \quad j=1, M
$$

The third constraint requires that imports be consumed or exported:

$$
\sum_{i=1}^{N} \sum_{t=1}^{T} x_{i j t}+z_{j}=y_{j}, \quad j=M+1, S .
$$

To show that the model can be simplified, define

$$
\begin{gathered}
F(\boldsymbol{X})=\sum_{i=1}^{N} \sum_{j=1}^{S} \sum_{t=1}^{T} c_{i j t} x_{i j t} \\
\boldsymbol{p}^{\prime} \boldsymbol{y}=\sum_{j=M+1}^{S} p_{j} y_{j} \\
q^{\prime} z=\sum_{k=1}^{R} q_{k} z_{k}
\end{gathered}
$$

The PEMEX objective function can the be written as

$$
F(X)+p^{\prime} y-q^{\prime} z
$$

Finally, let

$$
\Gamma(X, \boldsymbol{y}, \boldsymbol{z}, \boldsymbol{D}, \boldsymbol{Q}) \geq 0
$$

be the linear constraint set given by (A-2), (A-3) and (A-4). Let $\Omega(\boldsymbol{y}, \boldsymbol{z}, \boldsymbol{D}, \boldsymbol{Q})$ be the set of feasible allocations. We can first define the following problem of minimizing transport costs for a fixed value of imports and exports. This is given by the problem

$$
G(\boldsymbol{y}, z, \boldsymbol{D}, \boldsymbol{Q})=\min _{\boldsymbol{X}} F(\boldsymbol{X})
$$


subject to (A-9) for fixed values of $\boldsymbol{y}$ and $z$ in $\Omega(\boldsymbol{y}, z, D, Q)$. The Lagrangian for this problem is

$$
L=F(X)+\lambda \Gamma(X, y, z, D, Q)
$$

From the envelope theorem, we know

$$
\begin{aligned}
& \frac{\partial G}{\partial \boldsymbol{y}}=\lambda \frac{\partial \Gamma}{\partial \boldsymbol{y}} \\
& \frac{\partial G}{\partial z}=\lambda \frac{\partial \Gamma}{\partial z}
\end{aligned}
$$

Now consider the problem of minimizing the net cost of imported LPG given a vector of production and demands

$$
H(D, Q)=\min _{\boldsymbol{y}, z}\left[G(\boldsymbol{y}, z, D, Q)+p^{\prime} \boldsymbol{y}-\boldsymbol{q}^{\prime} z\right]
$$

The first order conditions for (A-14) are given by

$$
\begin{gathered}
\boldsymbol{p}+\frac{\partial G}{\partial \boldsymbol{y}} \geq 0, \quad \mathrm{y}\left[\boldsymbol{p}+\frac{\partial G}{\partial \boldsymbol{y}}\right]=0 \\
-\boldsymbol{q}+\frac{\partial G}{\partial z} \geq 0, \quad \mathrm{z}\left[-\boldsymbol{q}+\frac{\partial G}{\partial z}\right]=0 .
\end{gathered}
$$

If we substitute in the (A-15) and (A-16) from (A-12) and (A-13), we get

$$
\begin{gathered}
\boldsymbol{p}+\lambda \frac{\partial \Gamma}{\partial \boldsymbol{y}} \geq 0, \quad \mathrm{y}\left[\boldsymbol{p}+\lambda \frac{\partial \Gamma}{\partial \boldsymbol{y}}\right]=0 \\
-\boldsymbol{q}+\lambda \frac{\partial \Gamma}{\partial z} \geq 0, \quad \mathrm{z}\left[-\boldsymbol{q}+\lambda \frac{\partial \Gamma}{\partial z}\right]=0 .
\end{gathered}
$$


The problem defined by (A-14) has a dimensionality less than or equal to the number of import and export activities. The vector of shadow prices is determined by the linear system given by (A-17) and (A-18). It is independent of the particular structure of the function $F(\boldsymbol{X})$. The convexity of the feasible set and the assumption that the objective function is linear insures that the two problems have the same solution. Any objective function that maximize welfare as a function of the demands for gas will give the same results for the value of as the cost minimizing model as the price is ultimately determined by the constraints. 